
\title{
Besearch S Surare \\ Integration Study on Brainstorming and Extenics for Intelligent Innovation in the Big Data Environment
}

\section{Xingsen Li}

Guangdong University of Technology

\section{Haibin Pi}

Guangdong University of Technology

Libo Xu

Zhejiang University Ningbo Institute of Technology

\section{Zhenhao Yang}

Guangdong University of Technology

\section{Zhencheng Liang}

Guangdong University of Technology

Haolan Zhang ( $\square$ haolan.zhang@nit.zju.edu.cn )

Zhejiang University Ningbo Institute of Technology https://orcid.org/0000-0002-5033-1866

\section{Research Article}

Keywords: brainstorming method, Extenics, extension innovation method, divergent thinking, problem solving, human-computer interaction, basic-element theory

Posted Date: January 19th, 2022

DOI: https://doi.org/10.21203/rs.3.rs-1203485/v1

License: (c) (i) This work is licensed under a Creative Commons Attribution 4.0 International License.

Read Full License 


\title{
Integration Study on Brainstorming and Extenics for Intelligent Innovation in the Big Data Environment
}

\author{
Xingsen $\mathrm{Li}^{1}$, Haibin $\mathrm{Pi}^{1}$, Libo Xu ${ }^{2}$, Zhenhao Yang ${ }^{1}$, Zhencheng Liang ${ }^{1}$, Haolan Zhang ${ }^{2 *}$ \\ *Correspondence: haolan.zhang@nit.zju.edu.cn \\ ${ }^{1}$ Guangdong University of Technology, Guangzhou, 510006, China. \\ ${ }^{2}$ Ningbo Institute of Technology, Zhejiang University, China. \\ Full list of author information is available at the end of the article
}

\begin{abstract}
Brainstorming is widely used in problem solving, which generates a large number of innovative ideas by guiding and stimulating intuitive and divergent thinking. However, in practice, the method is limited by the brain capacity of both individuals and work teams, especially the experience and knowledge they possess. How do ideas come from the brains like storming? Based on the new discipline of Extenics, we propose a test that explores the process of how ideas are brought out of the brain, helping people think multi-dimensional and get more ideas. Extenics has been applied since 1983 to study the extension and transformation of things, and to obtain the creativity to solve contradictory problems intelligently. With the support of information technology and artificial intelligence, we systematically collect more information and knowledge to form a basic-element information base and build human-computer interaction models to make up for the limited information and knowledge in the human brain. In addition, we provide a methodology to help people think positively in a multidimensional way based on the guidance of the Extenics in the brainstorming process. The integration of Extenics with brainstorming method provides a systematic new direction for improving brainstorming method in big data environment. The case study initially verifies the effectiveness of our new method.
\end{abstract}

Keywords: brainstorming method; Extenics; extension innovation method; divergent thinking; problem solving; human-computer interaction; basic-element theory.

\section{Introduction}

Brainstorming (BS) is a method of stimulating creative thinking also known as intellectual stimulation which proposed by the American scholar Alex Osborne in 1938 [1]. It was first used as a term in Psychiatry to refer to the state of rumination caused by disordered thinking in psychiatric patients, and is now used as a proxy for the act of generating a large number of innovative ideas with a highly active mind and unrestricted free association and discussion. Brainstorming is a method based on the theoretical foundations of psychology and behavioral sciences, using intuitive and divergent thinking for generating new possible solutions to problems [2]. It is now widely used in creative thinking activities and is an effective method for developing creativity [3]. However, brainstorming relies heavily on human brain capabilities, especially the experience and knowledge they possess. Today's Internet environment provides good opportunities for innovation [4-5]. There is an increasing amount of information and knowledge emerging on the Internet that can be combined with brainstorming methods to fill the gaps in human knowledge and information.

Extenics has been applied to obtain systematic creativity by studying the extension and transformation of things in formal models and used to to solve contradictory problems intelligently based on the theory of extension sets, basic-element theory and extension transformation methods since 1983[6-8]. It uses a set of ideological system and theoretical methods that can facilitate innovation again after practicing, summarizing, and constantly 
improving the innovation process, and its fundamental role is to inspire people's thinking and enhance the innovation efficiency in the actual innovation process [9]. The extension innovation method is a formal and quantifiable method used to expand, transform, reason, and judge the contradictory problems in the innovation process to generate ideas for solving various contradictory problems with the basic theory of Extenics [10].

Innovation is playing an increasingly important role in research and business [11], and the brainstorming method is used more and more widely. However, some shortcomings of the method have been found in the process of practice, and many improvement solutions have been proposed by scholars, such as the use of computers for anonymous brainstorming to solve the interference of subjective factors [12], etc. In this paper, we introduce Extenics theory to address the shortcomings of the brainstorming process, which relies too much on personal ability and experience, and combine the extension innovation method, which is characterized by the essence of formalized idea generation, to conduct the research and exploration of optimization and upgrading of brainstorming method.

The rest of our paper is organized as following. The second section of this paper analyzes the characteristics, shortcomings, and general application process of the brainstorming method. The third section introduces the basic ideas of Extenics theory and the application of the extension innovation method. Then proposes the basic idea of integrating Extenics and brainstorming methods, and designs the general application process and human-computer interaction model of the new brainstorming method with the support of information technology and artificial intelligence. The fourth section give the results and initially verifies the effectiveness of the new method through application cases. Finally, the last section "Discussion” is after "Results” section.

\section{Analysis on Brainstorming method}

\subsection{Principles of brainstorming}

Brain storming is known as intellectual stimulation method or free thinking method, include free talk, free meeting, collective thinking etc. and can be divided into direct brainstorming method (usually referred to as brainstorming method) and questioning brainstorming method (also known as anti brainstorming method). The association reaction, enthusiasm infection, competitive consciousness and personal desire in the process form a series of internal excitation mechanisms. The brainstorming method has been studied and developed by scholars in various countries and has formed a multi-style group of methods and techniques that are widely used in business and teaching [13]. The brainstorming method allows the participants to express their ideas freely, so that each participating member can put forward ideas and creativity in a suitable place and a relaxed and free environment, and inspire each other, motivate each other, and associate with each other, so that the participants can generate resonance and chain reaction of thinking, thus inducing more ideas and creativity and more suggestions, so that the participants can inspire each other and thus break through various thinking barriers and psychological constraints[14]. In essence, people are expected to overcome their thinking stereotypes in which the focus of attention is on the imagination, association, intuition, inspiration, and other non-logical thinking process based on existing experience. Therefore, it must be solved in a certain quantity, and then the quantity to ensure the quality of the solution. The more ideas people come up with, the more likely they are to get the right answer to a problem. Therefore, the brainstorming method needs to meet the following basic principles: the principle of free thinking, the principle of delayed judgment, the principle of quality by quantity, and the principle of comprehensive improvement. Each of the four principles has its own focus and complements each other [15].

According to the gradual analysis of the stimulating mechanism of brainstorming, association is the basic process of generating new ideas. In the process of collective discussion, each new idea can trigger the association of others, produce a series of new ideas, produce chain reactions and form a pile of new ideas. It provides more possibilities for solving problems creatively. In terms of enthusiasm infection, without any restrictions, everyone can speak freely, influence and infect each other, which can form an upsurge, break through the shackles of inherent ideas and give full play to creative thinking ability to the greatest extent. With a sense of competition, 
everyone competes to speak, constantly starts the thinking machine, and strives to have unique opinions and novel ideas. In the process of collective discussion and problem-solving, it is very important that the individual's desire is free from any interference and control, that is, in the process, we should not criticize and speak hastily, and do not show suspicious expressions, actions and looks. Only in this way can everyone speak freely and put forward a large number of new ideas.

\subsection{General process of brainstorming method}

Brainstorming can be divided into three stages, namely preparation stage, brainstorming stage, and evaluation and selection stage. In Preparation stage: the purpose of the brainstorming is made clear, the problem statement should be specific, while the statement should be open enough to make the participants generate new and innovative thinking but not deviate from the theme. provide an external environment suitable for generating creativity and focus attention.

Brainstorming stage: explain the reasons for brainstorming, clarify the issues to be discussed, considerations, and determining the basic principles of the discussion and the order in which the group members will speak. This is followed by free speech, encouraging the participants to become creative, while the recorder records the inspiration and ideas stimulated by the participants, and finally concludes the meeting.

Evaluation and selection stage: the meeting record were first organized and classified and presented to all participants, then evaluate each creative idea in terms of effectiveness and feasibility, and finally selected the most suitable solution [16].

Brainstorming is a simple process without too many restrictions and constraints. The learning cost is relatively low. The method involves a group of people exploring specific topics and issues together, and the joint exploration process can be more exciting and dynamic[17]. The brainstorming method solves the limitations of designers' limited knowledge and subject areas, gives full play to the function of "brainstorming", and improves the innovation of understanding [18].

Through brainstorming, we can eliminate the compromise scheme, and find a group of practical schemes through objective and continuous analysis of the problems discussed. Of course, the implementation cost of brainstorming method (time, cost, etc.) is very high. However, brainstorming method requires participants to have better quality. Whether these factors are satisfied or not will affect the effect of brainstorming.

\subsection{Shortcomings of brainstorming method}

As an innovative method, brainstorming has outstanding advantages, but it is undeniable that there are still many problems need to be improved in its practical application, mainly reflected in the following points: Firstly, the brainstorming process lacks an effective intelligent method to support it, which makes divergent thinking lack systematicity and often only solves relatively simple problems. It can only stimulate the original talents of the participants, and most of the ideas generated are not pioneering ideas [19].

Secondly, the average quality of individual ideas is poor. The number of plans is high, but the quality is not good enough and even deviates from the topic and the issue under discussion. When communicating and discussing, it was impossible to judge the comprehensiveness of differences, lacked logic and structure, and ignored the levels or perspectives that should be noted.

Thirdly, the success of brainstorming depends on the ability and experience of individuals. In the practice of numerous brainstorming methods, the results achieved vary, and the professional backgrounds of group members are too far apart to possibly elicit enlightening thoughts [20-21], and their quality and efficiency are often easily affected by the knowledge and abilities of the participants and facilitators [22].

Furthermore, brainstorming requires participants to do divergent thinking and jumping thinking as much as possible, encourage random and irregular ideas. However, in reality, the randomness is not easy to control, which is easy to cause the dispersion both of form and spirit. More over, a widely accepted conceptualization assumption is that the quality of ideas increases as the number of unique ideas increases. However, observational studies through many brainstorming sessions have shown that the order, in which ideas are presented, can have an impact on the outcome 
of the brainstorming method [23]. Also, some psychological studies have shown that group think can blind us to connections we might find on our own or discourage us from expressing different ideas, and that teamwork can reduce our ingenuity and creativity [24].

In response to these shortcomings, a few improvements and optimizations have been proposed by scholars. Electronic brainstorming (EBS) and proposed methods have been studied such as using computers for anonymous brainstorming to address the interference of subjective factors[12]. Some researchers have proposed a mixture of other innovative methods to overcome the weaknesses of brainstorming. Providing some structure to brainstorming sessions by asking a series of questions or requiring participants to engage in specific activities can also make the sessions more productive [25]. Some scholars also point out that the key point of innovation method research is to strengthen the integration and application of innovation methods, and to analyze the relevant laws and theoretical foundations based on induction and combing, to promote the development of innovation from the source[26]. Liu Feng et al. proposed open discussions and proposals according to the structure during the brainstorming process, emphasizing the construction of the structured problem decomposition to optimize their mastery and utilization of structured knowledge of one or several types of problems, thus forming a sustainable improvement capability[22].To break the barriers of inertia and limited knowledge, some scholars propose to combine TRIZ and brainstorming method to support the abstraction of domain problems and the concretization of TRIZ general solutions, to obtain the ideal solutions with higher innovation[18]. By combining Brainstorming and TRIZ, people can quickly and effectively solve the problem of innovative design methods for product forms [27].

With the support of the information and artificial intelligence, we systematically collect more information and knowledge to make up for the limited information and knowledge in the human brain. Then we combined the theory of Extenics with the application of brainstorming method to help people think in multiple dimensions and come up with more ideas by the guidance of extension innovation methods.

\section{Process of new intelligent brainstorming method combined with Extenics}

3.1 Overview of theory and methods on

\section{Extenics}

Extenics is a new inter-discipline based on mathematics, philosophy and information science founded by Professor Cai Wen to study the possibility of expansion of things and the methods to solve contradictions and paradoxical problems with formal models. Extenics provides new theory of extension sets, basic-element theory and the method of extension transformations, and obtains the creativity systematically to solve the complicated problems intelligently $[6,28]$.

The basic-element theory defines the basic elements of "Matter-element" (all physical and non-physical existence), "Affair-element" (events or actions between things), and "Relation-element" (the relationship between things or affairs) to model information. A one-dimensional basic-element is an ordered triad consisting of an object, a characteristic and a corresponding measure, denoted as $M=(O, c, v)$, where $M$ represents the Matter-element; $c$ is the characteristic of $M ; v$ is the measure of $M$ to the characteristics $c$, the event element $A=(E, c, v)$ and the relation element $R=$ $(N, c, v)$. The use of Basic-element theory for modeling information can guide us to collect information in a systematic and unified structure [16].

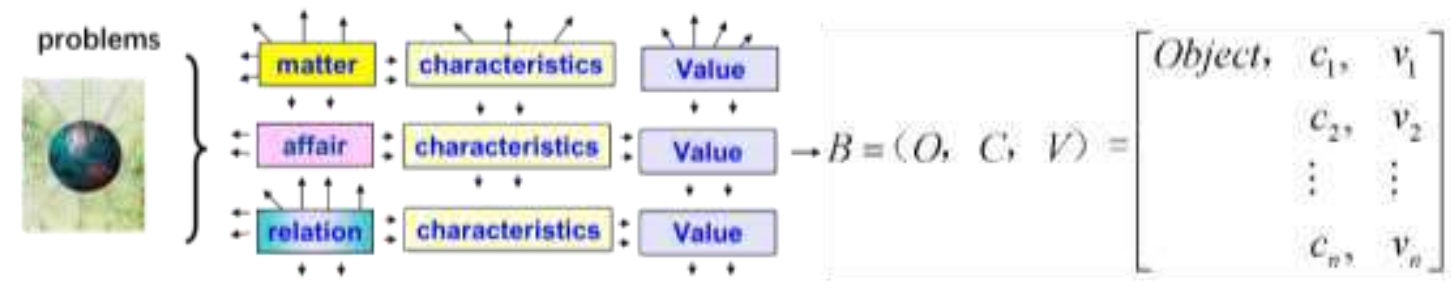

Figure 1. The basic-element theory-based information structure

Where $O$ denotes an object, $c_{1}, c_{2}, \ldots, c_{n}$ denote 
the $n$ attributes of object $O$, and $v_{1}, v_{2}, \ldots, v_{n}$ denote the corresponding quantitative values of object $O$ with respect to the above characteristics.

Basic-element theory can guide us to collect information in a systematic and unified structure. Things change over time, so we usually use dynamic matter with multiple properties to represent information about the Matter-element as follows.

$$
M(t)=\left[\begin{array}{ccc}
O_{m}(t), & c_{m 1}, & v_{m 1}(t) \\
& c_{m 2}, & v_{m 2}(t) \\
& \mathrm{M} & \mathrm{M} \\
& c_{m n}, & v_{m n}(t)
\end{array}\right]=\left(O_{m}(t), C_{m}, V_{m}(t)\right)
$$

By using Basic-element theory, our otherwise divergent thinking becomes structured, and basic-elements lead us to think in all possible directions in multiple dimensions.

The basic expansion methods include conjugate analysis, divergence analysis, correlation analysis, implication analysis, and expandability analysis, and by applying these methods, we provide a systematic direction for divergent thinking, which in turn makes it easier for us to get a variety of innovative ideas and creativity[9]. The elements of extensible thinking can be summarized as follows in table 1.

Table 1. systematic directions and methods for extensible thinking

\begin{tabular}{|l|l|}
\hline Three paths & $\begin{array}{l}\text { conditional transformation, target } \\
\text { transformation, both target and } \\
\text { conditional transformation }\end{array}$ \\
\hline $\begin{array}{l}\text { Four expansion } \\
\text { methods }\end{array}$ & $\begin{array}{l}\text { extensions of divergence trees, } \\
\text { correlation networks, implication } \\
\text { systems, divergent chains and } \\
\text { conjugate analysis }\end{array}$ \\
\hline $\begin{array}{l}\text { Five basic } \\
\text { transformations }\end{array}$ & $\begin{array}{l}\text { Substitution transformation, } \\
\text { Addition/deletion transformation, } \\
\text { Increase/decrease transformation, } \\
\text { component transformation, } \\
\text { Replication transformation }\end{array}$ \\
\hline Four operations & and, or, product, inverse \\
\hline
\end{tabular}

In practical applications, Basic-element modeling can be carried out according to the conditions and goals of the problem, and the divergent Basic-element can be combined to construct Basic-element base to solve contradictory problems.

\subsection{Extension innovation methods}

The extension innovation method is an operable idea generation method and invention creation [7,10] based on the basic theory of Extenics, which has a wide application in design idea generation and solving the contradictory problems in the design process and broad application in many fields [32].

In the network environment, a large amount of information and knowledge have become important resources for innovation. In recent years, design innovation through the application of extension innovation methods has also become more and more widespread, such as the design of cell phone charger products by integrating Extenics and TRIZ theory [33], and the study of technological innovation process based on extension innovation methods for the mechanical innovation design of petroleum machinery products [34].It is a set of ideas and theoretical methods to extension innovation again after practicing, summarizing, and constantly improving the innovation process, and its fundamental role is to inspire people's thinking and improve the innovation efficiency in the actual innovation process based on scientific laws [9].

The application of the extension innovation method can be divided into four steps: modeling, expansion, transformation, and selection, which is also called the four-step method of extension innovation. It calculates the compatibility of the problem by building a topological model of the problem, using the correlation function, and then performs expansion analysis, conjugate analysis, and topological transformation on the problem, and evaluates it by superiority, to obtain a better feasible solution to the problem[9]. The general steps for solving incompatible problems using the extension innovative thinking approach are as follows $[7,35]$.

(1) Modeling. Formalize the conditions and objectives of the contradictory problem in terms of basic-elements and identify the core conflict attributes and quantities that generate the contradictions.

(2) Expansion. Extend the target or condition separately to find the extended extension set of basic-elements by correlation analysis, conjugate analysis, extensible analysis and implication 
analysis.

Suppose $B$ as a basic element, $(O, c, v)$ is an object, $c$ denotes the attribute of object $O$, and $v$ denotes the corresponding quantitative values of $c$. The conjugate analysis can be shown as follows:

$$
\begin{array}{ll}
B=(O, c, v) \text { a } & \left\{\left(O, c_{1}, v\right),\left(O, c_{2}, v\right), \ldots,\left(O, c_{n}, v\right)\right\} \\
B=(O, c, v) \text { a } & \left\{\left(O_{1}, c, v\right),\left(O_{2}, c, v\right), \ldots,\left(O_{n}, c, v\right)\right\}
\end{array}
$$

The implication analysis is: $B \Rightarrow\left\{B_{1}, B_{2}, \ldots B_{n}\right\} \Rightarrow\left\{\left\{B_{11}, B_{12}, \ldots, B_{1 m}\right\},\left\{B_{21}, B_{22}, \ldots, B_{2 m}\right\}, \ldots\left\{B_{n 1}, B_{\text {. from }}, \ldots, B_{n m}\right\}\right\}$ the thansformation, calculate the

The extensible analysis is:

$$
\begin{aligned}
& B=B_{1} \oplus B_{2}=\left[\begin{array}{r}
O_{1} \oplus O_{2}, c_{1}, v_{1} \oplus c_{1}\left(O_{2}\right) \\
c_{2}, c_{2}\left(O_{1}\right) \oplus v_{2}
\end{array}\right] \\
& B=(O, c, c(O))=\left\{\left(O_{1}, c, c\left(O_{1}\right)\right),\left(O_{2}, c, c\left(O_{2}\right)\right)\right.
\end{aligned}
$$

(3) Transformation. From the basic-element, criterion, and domain, respectively, transform the original objective or condition into a multitude of available options through five basic transformations and four operations. The five basic transformations include substitution, addition and deletion, increase and decrease, subdivision and replication. The four operations are and, or, product, and inverse.

Suppose $\Gamma \in\{M, A, R, k, U\}, M, A, R$ denotes matter element, affair element and relation element, $k$ denotes criterion, and $U$ denotes domain. $T$ is the evaluation method, and the decision maker selects

transformation operation. Then, five basic transformations are listed as follows:

$$
\begin{aligned}
& T_{\text {substitution }} \Gamma=\Gamma^{\prime} \\
& T_{\text {addition }} \Gamma=\Gamma \oplus \Gamma_{1} \\
& T_{\text {increase }} \Gamma=\alpha \Gamma \\
& T_{\text {subdivision }} \Gamma=\left\{\Gamma_{1}, \Gamma_{2}, \ldots, \Gamma_{n}\right\}, \quad\left(\Gamma_{1} \oplus \Gamma_{2} \oplus \ldots \oplus \Gamma_{n}=\Gamma\right) \\
& T_{\text {replication }} \Gamma=\left\{\Gamma, \Gamma^{*}\right\}, \quad\left(\Gamma \approx \Gamma^{*}\right)
\end{aligned}
$$

(4) Evaluation. Evaluate the solutions the better solutions.

\subsection{Process of combined brainstorming and extension innovation method}

\section{$\left.\left.O_{n}, c, c\left(\Theta_{\mathrm{e}}\right)\right)\right\}_{\text {propose a brainstorming method }}$} integrating the extension innovation method, which is characterized by the essence of formal generation of ideas and quantitative scoring to improve the general application process of the brainstorming method. We try to explore the process of how ideas are generated from the brain, help people think in multiple dimensions and put forward more ideas systematically. We define the problem from the conditions and objectives, and divide all participants into several groups according to Extenics. The new process is shown in Figure 2.

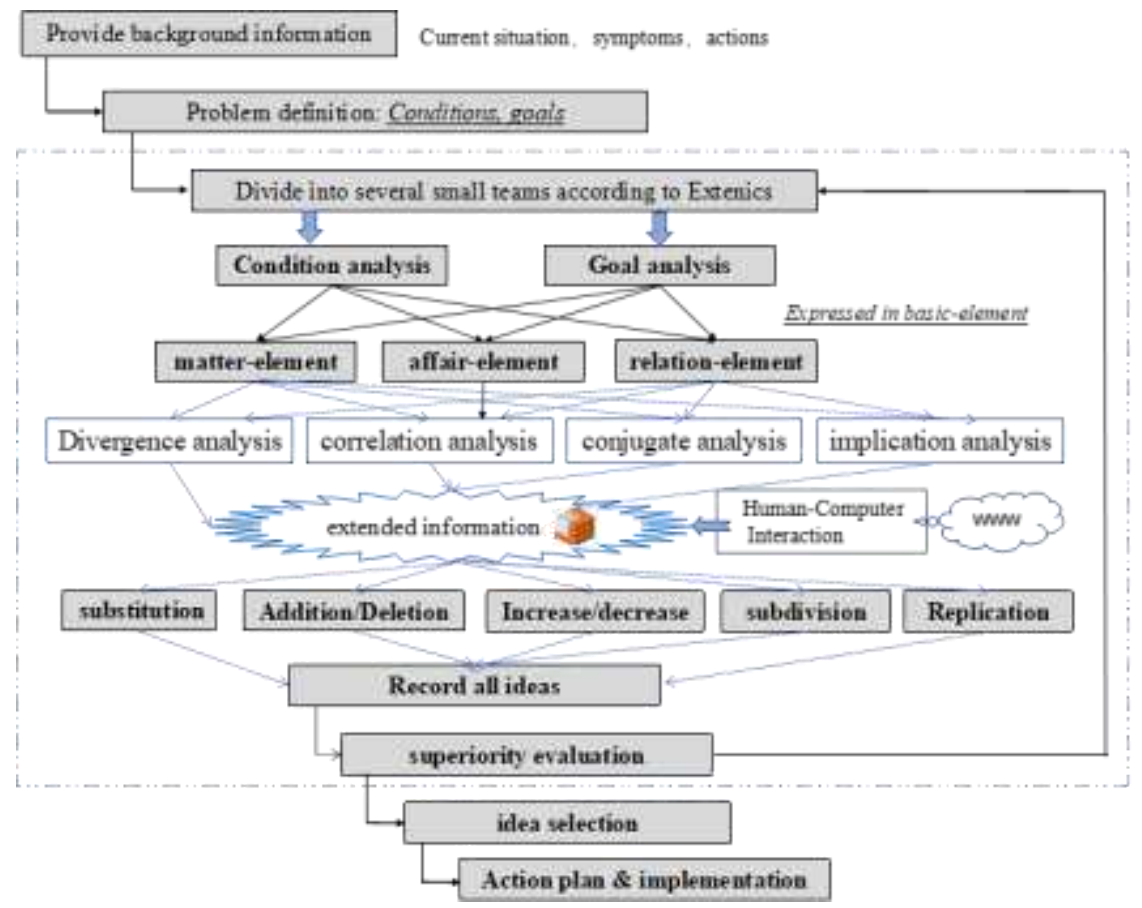

Figure 2. Extenics-based brainstorming process 
The detailed steps are as follows:

Step 1: Problem analysis. Analyze the problem from the conditions and goals according to the existing background and relevant information, and divide the participating members into two groups: One of analysis conditions is called group $L$, and the other of analysis targets is called group $G$. Find out the hypothesis that the existing conditions cannot achieve the goal, list what sufficient conditions are needed to achieve the goal, and we determine whether the goal to be achieved is the goal we really need? What is the ultimate goal of achieving this goal? Are there other more concise ways to achieve the final goal?

Step 2: Basic-element analysis. On the basis of condition and goal analysis, combine $G$ group and $L$ group, and then regroup them into matter-element analysis group $G L_{1}$, affair-element analysis group $G L_{2}$, relation-element analysis group $G L_{3}$, Each group uses methods such as divergence analysis, correlation analysis, conjugation analysis, and implication analysis to list as many objects, characteristics, and values related to the topics of the group as possible. Support the team to think in a higher dimensions to get more objects, characteristics and their value.

Step 3: Collect the information obtained by each group in step 2, use the human-computer interaction model to search for more information on the Internet or the software of basic-element base, and obtain a multi-dimensional information database in basic-element format. The information about goals and conditions is relatively systematic and nearly all-round.

Step 4: Extension transformation. According to the five basic methods of extension transformation, the participants are divided into five groups $A, B, C$, $D, E$, such as substitution, increasing/decreasing, expansion/contraction, decomposition, and duplication. Each group generates new ideas according to the basic transformation method, and the groups then shift to different basic transformation methods in turn, recording all the ideas describe our conditions and objectives from almost all directions and improve the dimension of creating innovative ideas as much as possible.

Step 5: Combined with the superiority evolution method, we can score and select ideas from the technical requirements, economic requirements, social requirements and other required measurement indicators. Then better creative ideas can be carried out and finally be chose.

In addition to using the method of expansion and transformation to create new ideas, each group can also use the questioning brainstorming method in brainstorming to question and improve. This is a special procedure to evaluate the realistic feasibility of an idea or scheme drawn from the above process, so as to form a list of practical and feasible final ideas for solving the problems discussed. it is also necessary to absorb some expert opinions capable of making more accurate judgments on the implementation of the assumption. Based on extenics, questioning brainstorming method can effectively realizes the objective and continuous latent analysis of the problems discussed.

\subsection{Human-computer interaction methods to aid brainstorming}

As mentioned above to overcome the limitations of the individual or team's knowledge background and experience, we developed a software to collect a large amount of data and information from the knowledge graphs and by the use of Internet resources to construct a Basic-element base [30-31]. It can break through the team's original knowledge limitations and provide materials for innovation. Therefore, it makes the "innovation process" observable and the limitations of personal knowledge can be resolved to a certain extent by a human-computer interaction model based on Extenics.

With the Human-computer interaction model, the general steps for acquiring new ideas can be divided into the four steps in Figure 3.

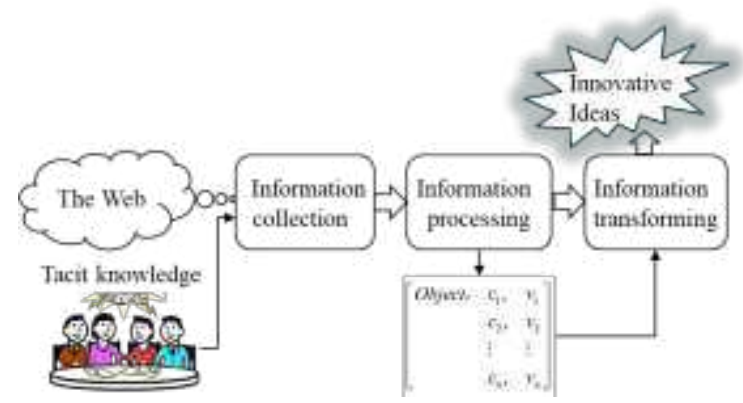

Figure. 3 Main steps for acquiring new ideas by human-computer interaction

Step 1. Collect information and knowledge

With the development of information technology, the Internet with big data and AI 
technology are changing the environment and has brought new opportunities for innovation[10, 36]. Behind the heterogeneous, rapidly changing and sparse big data, there are almost all the raw materials required for the generation of innovative ideas exist. Mining knowledge from big data to assist innovation is an inevitable trend in the future [36]. In the Internet age of data explosion, how to systematically and intelligently collect and process the required information and knowledge to provide requirements for brainstorming need support from data technology such as collect information and tacit knowledge related to innovation goals and practice conditions from the web by web crawlers and web mining.

\section{Step 2. Information processing}

Through the information technologies in step 1, the required information and knowledge have been obtained. Then, extenics is used to expand the information, study the expression and storage mode of ontology, realize the intelligent collection and storage of information and knowledge required for innovation, establish the basic element database, and continuously expand the innovative base for applications. Describe the information and knowledge as matter-element, affair-element or relation-element and save them in a table or database. Then build a extension information cube by conjugate analysis.

Step 3. Obtain possible ideas through

\section{transformation}

Combine the acquired multiple knowledge with people's empirical knowledge, and use the means of intelligent knowledge management [14] to find the deep knowledge and laws contained in the multiple knowledge. Apply the five basic transformation methods to transform the information cube in the basic element matrix to get possible ideas.

\section{Step 4. Select novel ideas}

From the above possible ideas, novel ideas are selected by AHP method or dependency function [7]. The evaluation criteria are both quantitative and qualitative.

Quantitative evaluation analysis generally needs to analyze the quantitative characteristics, quantitative relations and quantitative changes of new ideas based on certain mathematical knowledge, so as to reveal and describe the interaction and development trend of social phenomena. Qualitative analysis is the "qualitative" analysis of the research object, using the methods of induction and deduction, analysis and synthesis, abstraction and generalization to understand the essence of things and reveal the internal laws. The analysis of comprehensive qualitative evaluation and quantitative evaluation can realize the screening of novel ideas.

\section{Results and Case analysis}

\subsection{A classic case of snow cover affects the power supply problem}

Background: One year, the northern part of the United States was extremely cold, with heavy snowfall, and ice and snow on electric wires. Large-span electric wires were often broken by the snow, which seriously affected communications. U.S. power supply companies break the power supply lines due to heavy snow every year, causing huge economic losses. Snow sweeping the power supply lines every year consumes a lot of manpower and is of no avail. In the past, many people tried to solve this problem, but they failed to get what they wanted. The company manager applied the brainstorming method invented by Osborne to try to solve this problem, and held a brainstorming symposium. Technical personnel of different professions participated in the meeting.

Brainstorming: The meeting first asked them to abide by the four basic principles of brainstorming: First, free thinking. Second, delay judgment. Third, seek quality by quantity. Fourth, combine and improve. Subject to the rules of the meeting, the discussion began. Someone proposed to design a special wire snow blower; some people thought of using electric heating to dissolve ice and snow; others suggested using oscillation technology to clear snow; others suggested whether to bring a few large broomsticks and take a helicopter to sweep the wires. snow. Although everyone thought this idea of "sweeping the snow by plane" was funny, no one criticized it at the meeting. On the contrary, when an engineer was puzzled, after hearing the idea of using an airplane to sweep snow, his brain was suddenly shocked, and a simple, feasible and efficient method of clearing snow emerged. He thought that whenever the heavy snow passed, he would send out a helicopter to fly along 
the snow-covered electric wire, and rely on the high-speed rotating propeller to quickly fan the snow off the electric wire. He immediately put forward the new idea of "using a helicopter to fan the snow", which immediately aroused the association of other participants. There were seven or eight more ideas about using a plane to remove snow. In less than an hour, 10 technicians at the meeting put forward more than 90 new ideas.

Meeting result: After the meeting, the company organized experts to classify the ideas. Experts believe that it is technically feasible to design a special snow blower, using electric heating or electromagnetic oscillation to remove snow on the wires, but the development cost is large, the cycle is long, and it is difficult to achieve immediate results. The several ideas inspired by "sweeping snow by plane" are a bold new plan. If feasible, it will be a simple and efficient way. After field trials, it was found that using a helicopter to fan the snow really worked. A long-standing problem was finally solved in a brainstorming session.

\subsection{Apply the new brainstorming method with the extension innovation method}

Although the application of traditional brainstorming methods to solve the problem of snow on electric wires is classic, it has been found in practice that this solution maybe not the optimal solution. Therefore, the team reconvened the staff, applied the new brainstorming method with extension innovation method as following.

Step 1: Problem analysis. One set of analysis conditions is called group L, and the other set of analysis targets is called group G. Find out the hypothesis that the existing conditions cannot achieve the goal, list what sufficient conditions are needed to achieve the goal, and we determine whether the goal to be achieved is the goal we really need? What is the ultimate goal of achieving this goal? Are there other more concise ways to achieve the final goal?

The target and conditional basic-element obtained by group $G$ and group $L$ are as follows:

$$
\begin{aligned}
& \mathrm{P}=\mathrm{G} * \mathrm{~L} \\
& \mathrm{G}=\left[\begin{array}{lll}
\text { Remove, } & \text { Domination object, } & \text { Snowflake } \\
& \text { Place, } & \text { On the wire } \\
\text { time, } & \text { winter } \\
\text { efficient }, & \text { high } \\
\text { cost }, & \text { Low }
\end{array}\right] \\
& \mathrm{L}=\left[\begin{array}{lll}
\text { eradicate, } & \text { Domination object, } & \text { Snowflake } \\
& \text { Acting object, } & \text { Worker } \\
& \text { tool, } & \text { Shovel } \\
\text { efficient }, & \text { Low }
\end{array}\right]
\end{aligned}
$$

Step 2: divided the team into matter-element analysis group GL1, affair-element analysis group GL2, relation-element analysis group GL3, Some of the obtained matter-element are as follows:

$$
\begin{aligned}
& \mathbf{M}_{1}=\left[\begin{array}{ll}
\text { Worker, } & \text { employer, } \\
\text { Labor cost, } & \text { electricity company } \\
\text { Cost method, } & \text { salary }
\end{array}\right] \\
& M_{2}=\left[\begin{array}{lll}
\text { Snowflake, } & \text { state, } & \text { Solid state } \\
\text { Temperature condition, } & \leq 2{ }^{\circ} \mathrm{C} \\
\text { weight, } & 200 \mathrm{~kg} / \mathrm{m} 3
\end{array}\right]
\end{aligned}
$$

\begin{tabular}{|c|c|c|c|}
\hline \multirow{4}{*}{$A_{1}=$} & Remove, & Domination object, & Snowflake \\
\hline & & Acting object, & Worker \\
\hline & & Place, & electric wire \\
\hline & & $\begin{array}{l}\text { Way, } \\
\text { tool, }\end{array}$ & $\begin{array}{l}\text { Manual eradication } \\
\text { shovel }\end{array}$ \\
\hline
\end{tabular}

$\mathbf{M}_{3}=\left[\begin{array}{lll}\text { electric wire, } & \text { structure type, } & \text { Cable line } \\ & \text { Transmission type, } & \text { Alternating current } \\ \text { Material, } & \text { Composite material } \\ \text { Withstand the maximum tension, } & 2000 \mathrm{~N} \\ \text { Installation method, } & \text { Overhead } \\ \text { Support method, } & \text { telephone pole } \\ \text { Support point, } & 200 \mathrm{~m} / \text { piece }\end{array}\right]$

$$
\begin{aligned}
& \mathbf{M}_{4}=\left[\begin{array}{lll}
\text { telephone pole, } & \text { Interval, } & 200 \text { meters } \\
& \text { high, } & 10 \mathrm{~m} \\
& \text { Material, } & \text { cement }
\end{array}\right] \\
& \mathrm{M}_{5}=\left[\begin{array}{lll}
\text { Electricity, } & \text { Accepted object, } & \text { electric wire } \\
& \text { Voltage, } & {[35,220] \mathrm{kv}} \\
& \text { Current, } & \text { small } \\
& \text { Thermal effect, } & \text { small } \\
& \text { Magnetic effect, } & \text { weak }
\end{array}\right]
\end{aligned}
$$

Some of the obtained affair-element are as follows : 


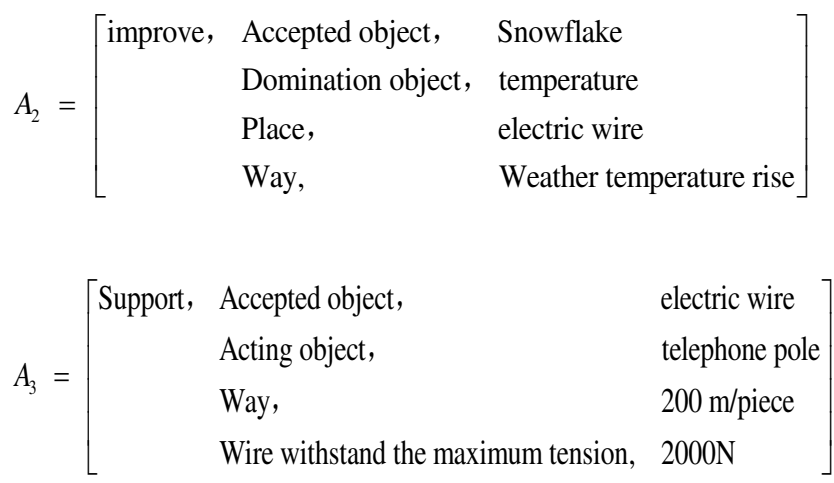

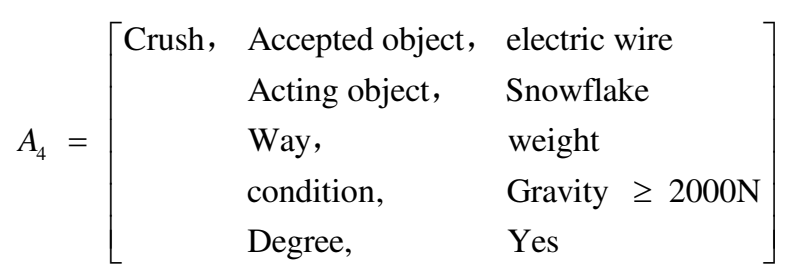

Some of the obtained relation-element are as follows:

$R_{1}=\left[\begin{array}{lll}\text { Attachment relationship, } & \text { Antecedent, } & \text { Snowflake } \\ & \text { Next item, } & \text { Power line } \\ & \text { Degree, } & \text { close }\end{array}\right]$

$R_{2}=\left[\begin{array}{lll}\text { Supporting relationship, } & \text { Antecedent, } & \text { electric wire } \\ & \text { Next item, } & \text { telephone pole } \\ & \text { Degree, } & \text { close }\end{array}\right]$

The results of matter-element analysis are as

follows:

$$
\begin{aligned}
& \mathrm{M}_{1}=\left[\begin{array}{lll}
\text { Worker, } & \text { employer, } & \text { electricity company } \\
& \text { Labor cost, } & 300 \mathrm{RMB} / \text { day } \\
& \text { Cost method, } & \text { salary }
\end{array}\right] \\
& \perp \mathrm{M}_{11}=\left[\begin{array}{lll}
\text { Worker, } & \text { employer, } & \text { Non-power company } \\
& \text { Labor cost, } & {[50,300] \mathrm{RMB} / \text { day }} \\
& \text { Cost method, } & \{\text { salary, bonus }\}
\end{array}\right] \\
& \perp \mathrm{M}_{111}=\left[\begin{array}{lll}
\text { Worker, } & \text { employer, } & \text { Local residents } \\
& \text { Location, } & \text { Near the wire } \\
& \text { Labor cost, } & 300 \mathrm{RMB} / \mathrm{day} \\
& \text { Cost method, } & \text { bonus }
\end{array}\right]
\end{aligned}
$$

$$
\mathbf{M}_{2}=\left[\begin{array}{lll}
\text { Snowflake, } & \text { state, } & \text { Solid state } \\
& \text { Temperature condition, } & \leq 0{ }^{\circ} \mathrm{C} \\
& \text { weight, } & 200 \mathrm{~kg} / \mathrm{m} 3
\end{array}\right]
$$$$
\perp\left\{\begin{array}{l}
\mathbf{M}_{21}=\left[\begin{array}{ll}
\text { Snowflake, } & \text { state, } \\
& \text { Temperature condition, } \\
\text { weight, } & {[0,100]{ }^{\circ} \mathrm{C}} \\
200 \mathrm{~kg} / \mathrm{m} 3
\end{array}\right] \\
\mathbf{M}_{22}=\left[\begin{array}{lll}
\text { Snowflake, } & \text { state, } & \text { Vapor state } \\
& \begin{array}{l}
\text { Temperature condition, } \\
\text { weight, }
\end{array} & 200 \mathrm{~kg} / \mathrm{m} 3
\end{array}\right]
\end{array}\right.
$$

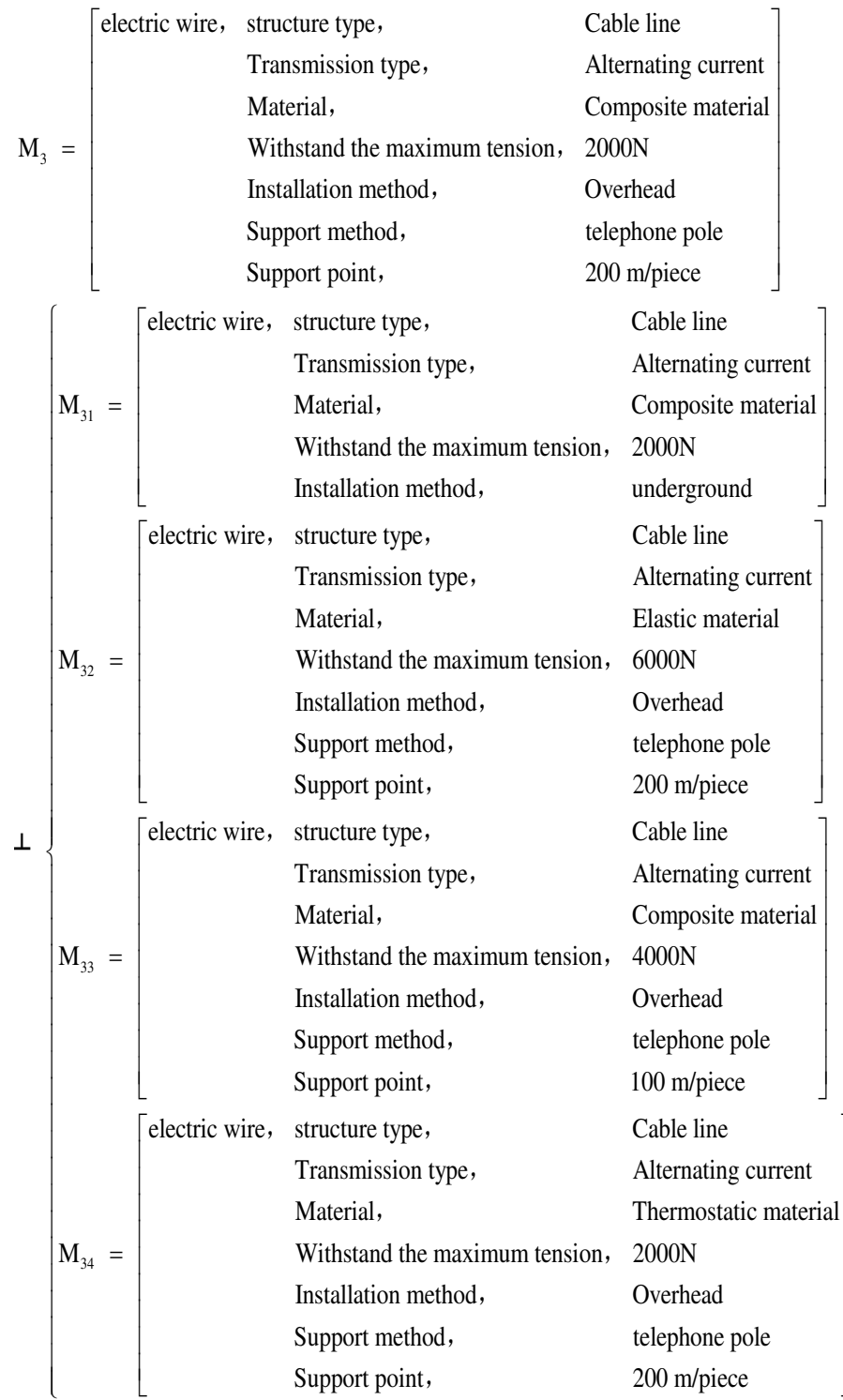

$$
\begin{aligned}
\mathbf{M}_{4}= & {\left[\begin{array}{rl}
\text { telephone pole, } & \text { Interval, } \\
\text { high, } & 200 \text { meters } \\
\text { Material, } & \text { cement }
\end{array}\right] } \\
& \perp\left\{\begin{array}{lll}
\mathbf{M}_{41}=\left[\begin{array}{lll}
\text { telephone pole, } & \text { Interval, } & 100 \text { meters } \\
& \text { high, } & 10 \mathrm{~m} \\
& \text { Material, } & \text { cement }
\end{array}\right] \\
\mathbf{M}_{42}=\left[\begin{array}{lll}
\text { telephone pole, } & \text { Interval, } & 150 \text { meters } \\
& \text { high, } & 10 \mathrm{~m} \\
& \text { Material, } & \text { cement }
\end{array}\right]
\end{array}\right.
\end{aligned}
$$$$
\mathrm{M}_{5}=\left[\begin{array}{lll}
\text { Electricity, } & \text { Accepted object, } & \text { electric wire } \\
& \text { Voltage, } & {[35,220] \mathrm{kv}} \\
& \text { Current, } & \text { small } \\
& \text { Thermal effect, } & \text { small } \\
& \text { Magnetic effect, } & \text { weak }
\end{array}\right]
$$$$
\perp\left\{\mathbf{M}_{51}=\left[\begin{array}{lll}
\text { Electricity, } & \text { Accepted object, } & \text { electric wire } \\
& \text { Voltage, } & {[35,220] \mathrm{kv}} \\
& \text { Current, } & \text { small } \\
& \text { Thermal effect, } & \text { Big } \\
& \text { Magnetic effect, } & \text { powerful }
\end{array}\right]\right.
$$

The results of affair-element analysis are as 

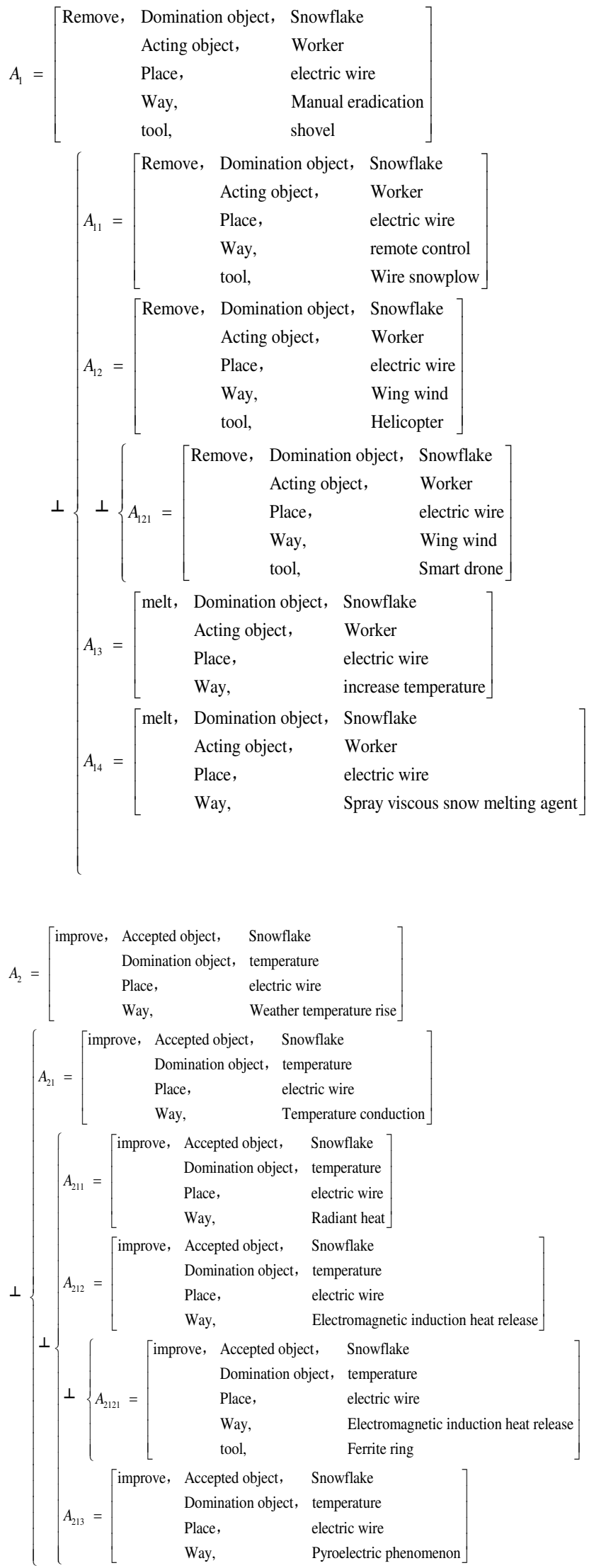

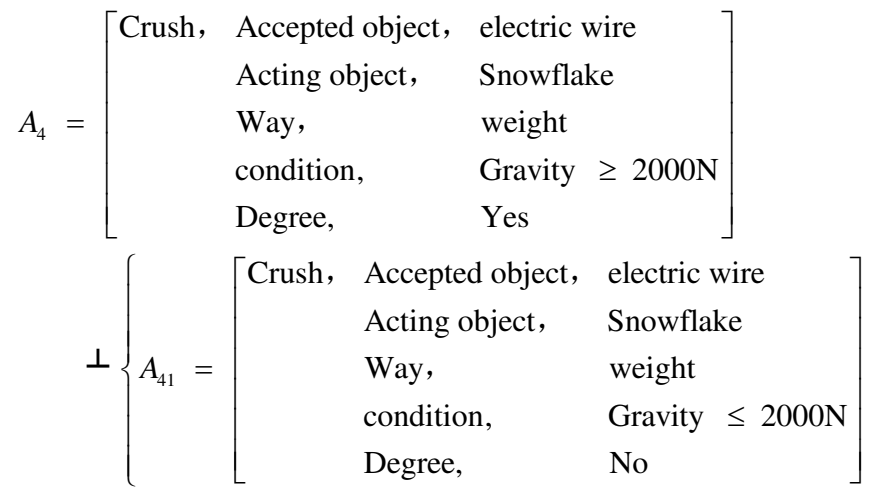

The results of relation-element analysis are as follows:

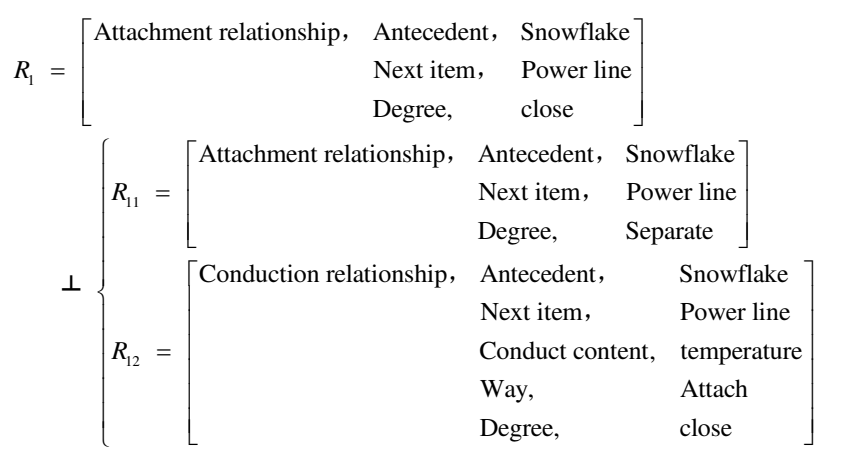

Step 3: Collect the information obtained by each group in step 2, use the human-computer interaction model to search for more information on the Internet, and obtain a multi-dimensional information database in basic-element format. For example, the effects that can be achieved through the Internet to increase the temperature are: conduction, convection, radiation, electromagnetic induction, pyroelectric medium, thermionic, discharge, material absorption of radiation, pyroelectric effect, object compression, nuclear reaction, etc. For example, when the Curie point of the ferrite ring is near $0^{\circ} \mathrm{C}$, the magnetic effect can generate heat when the temperature is lower than $0^{\circ} \mathrm{C}$, and the heating can be stopped when the temperature is higher than $0^{\circ} \mathrm{C}$, so that the purpose of working only on snowy days in winter can be achieved. The information about goals and conditions is relatively systematic and complete.

Step 4: Extension transformation. According to the five basic methods of extension transformation, electric wire the participants are divided into five groups A, B, C, $100 \mathrm{~m} /$ piece $\mathrm{D}, \mathrm{E}$, such as substitution, increasing/decreasing, 4000N expansion/contraction, decomposition, and 
duplication. Each group generates new ideas according to a basic transformation method, and the group then rotates different basic transformation methods in turn, recording all the ideas.

The possible solutions obtained are as follows:

$$
\mathrm{T}_{111} \mathrm{M}_{1}=\mathrm{M}_{111}=\left[\begin{array}{lll}
\text { Worker, } & \text { employer, } & \text { Local residents } \\
& \text { Location, } & \text { Near the wire } \\
& \text { Labor cost, } & 100 \mathrm{RMB} / \text { day } \\
& \text { Cost method, } & \text { bonus }
\end{array}\right]
$$

$\mathrm{T}_{21} \mathrm{M}_{2}=\mathrm{M}_{21}=\left[\begin{array}{lll}\text { Snowflake, } & \text { state, } & \text { Liquid } \\ & \text { Temperature condition, } & {[0,100]{ }^{\circ} \mathrm{C}} \\ & \text { weight, } & 200 \mathrm{~kg} / \mathrm{m} 3\end{array}\right]$

$T_{A 141} A_{14}=A_{11} \oplus A_{14}$

$$
\begin{aligned}
& \text { Remove, Domination object, Snowflake } \\
& \text { Acting object, Worker } \\
& \text { Place, electric wire } \\
& \text { Way, remote control } \\
& \text { tool, Wire snowplow } \\
& \text { [melt, Domination object, Snowflake } \\
& \oplus \quad \begin{array}{ll}
\text { Acting object, } & \text { Worker } \\
\text { Place, } & \text { electric wire }
\end{array} \\
& \text { Way, Spray } \\
& \text { tool, } \quad \text { viscous snow melting agent } \\
& \text { [Remove } \oplus \text { melt, Domination object, Snowflake } \\
& =\left[\begin{array}{lll}
\text { Remove } \oplus \text { melt, } & \text { Domination object, } \\
& \text { Acting object, } & \text { Snowflake } \\
& \text { Place, } & \text { Worker } \\
& \text { Way, } & \text { electric wire } \\
& \text { remote control }
\end{array}\right.
\end{aligned}
$$$$
=\mathrm{A} 141
$$

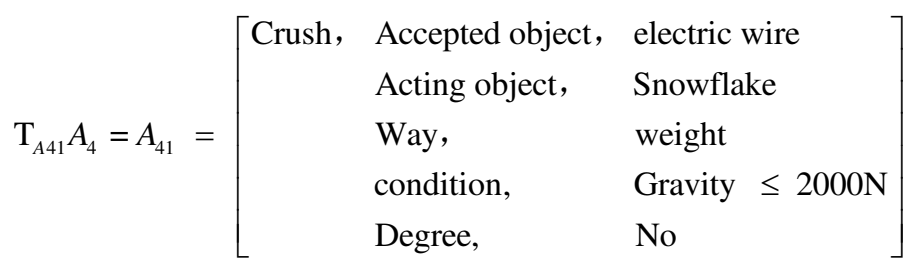

After the "and" operation again, we can get:

$$
T=T_{111} \wedge T_{21} \wedge T_{A 141} \wedge T_{A 41}
$$

Solution 1: Use bonuses to encourage local residents near telegraph poles to use remote snowplows to remove snow or spray viscous deicing agents to melt the snow into water, so that the snow cannot crush the telegraph poles and achieve the goal. The extension model is:

$$
D_{0}^{1}=M_{111} \wedge M_{21} \wedge A_{141} \wedge A_{41}
$$

In the same way, based on the space, the steps of extension transformation are omitted, and dozens of possible solutions are also obtained. For example, using worker drones to cruise and sweep snow, and using wing wind to remove snow on power lines, the extension model is: $D_{0}^{2}=M_{1} \wedge M_{2} \wedge A_{121} \wedge A_{41}$;
Use the wind of the wing to remove the snow on the wires and install the overhead wires to the ground to solve the snow problem, the extension model is: $D_{0}^{3}=M_{31} \wedge R_{11} ;$ Change the original wire material to elastic material to increase the wire's ability to withstand tension, the extension model is: $D_{0}^{4}=M_{32} \wedge A_{41} ;$ Add telegraph poles, so that the wires can be supported by more points of support, the extension model is: $D_{0}^{5}=M_{33} \wedge M_{41} \wedge A_{31} \wedge A_{41} \wedge R_{2} ;$ Install a ferrite ring with a Curie point near $0^{\circ} \mathrm{C}$ on the wire to increase the electromagnetic induction heat, increase the wire temperature, and melt the snow by the wire conduction temperature, the extension model is: $D_{0}^{6}=M_{21} \wedge M_{34} \wedge M_{51} \wedge A_{222} \wedge A_{2241} \wedge R_{2}$ etc.

Step 5: In the evaluation and optimization process, after obtaining the above-mentioned many possible solutions, for the difficult-to-select solutions, the required measurement indicators such as creative technical requirements, economic requirements, and social requirements can be evaluated and analyzed according to this method. Introduce the excellentness evaluation method in the extension innovation method for selection.After the extension optimality evaluation, it is concluded that both scheme 1 and scheme 6 are feasible solutions, which solves the practical problems for the company.

\section{Discussion}

Previously, as we could not observe the innovation process well, so we did not know how innovative ideas were generated. Based on the new discipline of Extenics and brainstorming method, we will propose a test method with the help of electroencephalography (EEG) to explore the process of how ideas are brought out from the brain [13-14] to help people to think in multiple dimensions. and come up with more ideas. On the one hand, integration application study for Extension innovation method makes up for many defects in brainstorming, such as lack of scientific methods, poor average quality of personal ideas, too personal ideas, and uncontrollable. On the other 
hand, complete the creation modeling and full coverage of creativity through extenics, guide participants to brainstorm according to the process, form directional divergence, and avoid uncontrollable results caused by too randomness. On this model, it can also generate candidate ideas with sufficient coverage, reduce the quality requirements of participants, improve the lower limit of brainstorming, ensure the creative breadth and controllability of brainstorming, and effectively improve the efficiency of brainstorming.

With the support of information technology and artificial intelligence, we will systematically collect more information and knowledge, form the basic elements based on Extenics based and use human-computer interaction models to help people discover more features and their values. This will compensate for the limited information and knowledge in the human brain. In addition, we will provide our methodology to help people think positively in multiple dimensions based on the guidance of our new model.

\section{Acknowledgment}

The authors would like to thank Prof. Chunyan Yang from GDUT for her suggestions on this project.

\section{Availability of data and materials}

Data sharing not applicable to this article as no datasets were generated or analyzed during the current study.

\section{Declarations}

\section{Competing interests}

The authors declare that they have no competing interests.

\section{Authors' contributions}

The model is designed and performed by Xingsen Li and Haolan Zhang. The paper is written by Haibin Pi, Zhenhao Yang and Zhencheng Liang, modifified and optimized by Libo Xu and Xingsen Li. All the authors read and approved the final manuscript.

\section{Authors' information}

Xingsen Li, Guangdong University of Technology, Guangzhou, 510006, China.

Haibin Pi, Guangdong University of Technology, Guangzhou, 510006, China.

Libo Xu, Ningbo Institute of Technology, Zhejiang University, China.

Zhenhao Yang, Guangdong University of Technology, Guangzhou, 510006, China.
Zhencheng Liang, Guangdong University of Technology,

Guangzhou, 510006, China.

Haolan Zhang, Ningbo Institute of Technology, Zhejiang University, China.

\section{Funding}

This work is partially supported by National Natural Science Foundation of China (No.72071049) and Humanity and Social Science Foundation of the Ministry of Education of China (18YJAZH049).

\section{Author details}

1 Guangdong University of Technology, Guangzhou, 510006, China. 2 Ningbo Institute of Technology, Zhejiang University, Ningbo, China

\section{References}

[1] Shui, Z.: Introduction to Brainstorming[J]. Academic Degrees \& Graduate Education,(01):44,(2003).

[2] CHAE K. :Alex 0sborn\&brainstorming,(1997). [3]Wu, X.: Higher Education Psychology.Beijing: Higher Education Press,(1999).

[4] Zhuang, Y., Wu, F., Chen, C., Pan, Y.: Challenges and opportunities: from big data to knowledge in AI2.0. Front. Inf. Technol. Electron. Eng. 18(1), 3-14 (2017).

[5] Li, X., Tian, Y., Smarandache, F., Alex, R.: An extension collaborative innovation model in the context of Big Data. Int. J. Inf. Technol. Decis. Making 14(1), 69-91(2015).

[6] Yang, C., Cai, W. :Extenics: Theory. Method and Application. Science Press, Beijing (2013).

[7] Yang, C.:Extension Innovation Method. CRC Press, Cornwall (2019).

[8] Yang, C., Cai, W.: Extension Engineering.Beijing: Science Press,(2007).

[9] Li, X., Zhang, L.: Extension of innovative thinking and training. Beijing: Machinery Industry Press, (2016). [10] Yang, C., Li, X.: Research Progress in Extension Innovation Method and its Applications. Industrial Engineering Journal,15(01): 131-137,(2012).

[11] Chen, J., Lv, W.: Innovation study: evolution and contribution of China. Technol. Econ. 37(5),1-13 (2018).

[12] Wang, K., Xi, Y., Wang, Y.: Research on Electronic Brainstorming (EBS). Systems

Engineering,(05):1-8,(1994).

[13] Wu, J.: On the network application of brainstorming method. Information Science, (06):749-751,(2004).

[14] Guest, G, Namey, E, Taylor, J.: Comparing focus 
groups and individual interviews: findings from a randomized study[J].International Journal of Social Research Methodology,20(6),693-708,(2017).

[15] Nie, H., Yuan, F.: Innovative techniques and application research of TRIZ. Machinery Design \& Manufacture, (10):218-219,(2007).

[16] A F Osborne. :Creative imagination. Wang Mingli, et al. Guangzhou: Guangdong People's Publishing House, (1987).

[17] Wang, H., Wu, R., Lu, D.: A summary of brainstorming. Journal of Jilin Province Economic Management Cadre College, (05):55-57,(2005).

[18] Chen, H., Ren, G.: Research on the promotion of creative thinking by TRIZ and brainstorming. Machinery Design \& Manufacture,

(11):268-269+272,(2013).

[19] Liu, F., Li, Z.: Innovation and Application of Structured Brainstorming. Journal of Commercial Economics, (25): 94+117,(2010).

[20] Litchfield, R. C., J. Fan , and V. R. Brown.: Directing idea generation using brainstorming with specific novelty goals. Motivation \& Emotion,35(2):135-143,(2011).

[21] Xue, L.: Magical brainstorming method[J].

Business Research, (05): 61-62,(2005).

[22] Liu, F., Li, Z.: Innovation of structured brainstorming method and its application. Business Times,No.500(25):94+117,(2010).

[23] Danes, J E.; Lindsey-Mullikin, J; Lertwachara, K.: The sequential order and quality of ideas in electronic brainstorming, International Journal of Information Management, 53, 102126,(2020).

[24] Stroebe W, Nijstad B A, Rietzschel E F .: Beyond Productivity Loss in Brainstorming Groups. Advances in Experimental Social Psychology,

43(10):157-203,(2010).

[25] Gobble, MaryAnne M. :Beyond

brainstorming.Research Technology Management, 57(2): 60-62, (2014).

[26] Zhang, S., Men, Y., Shan, C.: Research on the integration and application of multiple innovation methods. Industrial Technology and Economics, 265(11):154-160,(2015).

[27] Guo, X., Zhao, C., Hu, Z., Fan, J., Li, P.: Study on the innovation method of BS and TRIZ integrated product form. Mechanical

Design,v.31;No.299(09):101-104,(2014).

[28] Cai, W., Shi, Y.: The scientific significance and future development of Extenics. Journal of Harbin
Institute of Technology, (07): 1079-1086,(2006).

[29] Cai, W.,Yang, C.: Basic theory and methodology on Extenics. Chinese Science Bulletin,

58(13):1190-1199,(2013).

[30] Yu, Z., Li, X.: Modeling of Basic-element and Its Application. Journal of Guangdong University of Technology ,32(03):5-9,(2015).

[31] Li, X, Liu, Y.: Study on the Relationship among Extenics, Information Management and Knowledge Management in the Knowledge Economy.

Contemporary Economic

Management ,33(11):6-9,(2011).

[32] Yang, C., Luo, L.: Application of Extension Innovation Method in Product Design. Packaging Engineering, 37(14):7-10,(2016).

[33] Guo, H., Li, X., Liu, R.: A Creative Generation Method of Product Design Based on Extenics and TRIZ - Taking the Design of Mobile Phone Charger as an Example. Journal of Guangdong University of Technology,38(2):20-25,(2021).

[34] Zhang, H, Yang, K.: Research on Technological Innovation Process Based on Extension Innovation Method_— Taking Petroleum Machinery Products as an Example. Journal of Mathematics in Practice and Theory, 37(05):7-12,(2020).

[35] Yang, C., Cai, W.: Generating Creative Ideas for Production Based on Extenics. Journal of Guangdong University of Technology, 33(01): 12-16,(2016).

[36] Xu L.,Pan X., Yuan P.: Knowledge innovation by intelligent emergence: concept, framework and its pathway, CAAI transactions on intelligent systems, 12( 1) : 47-54. (2017), DOI:10.11992/tis.201610014 